\title{
Factors affecting family physicians' drug prescribing: a cross-sectional study in Khuzestan, Iran
}

\author{
Mohammad Arab $^{1}$, Amin Torabipour ${ }^{1,2, *}$, Abbas Rahimifrooshani ${ }^{3}$, Arash Rashidian ${ }^{1}$, Nayeb Fadai ${ }^{1}$, 3PP PIid [ TBP
}

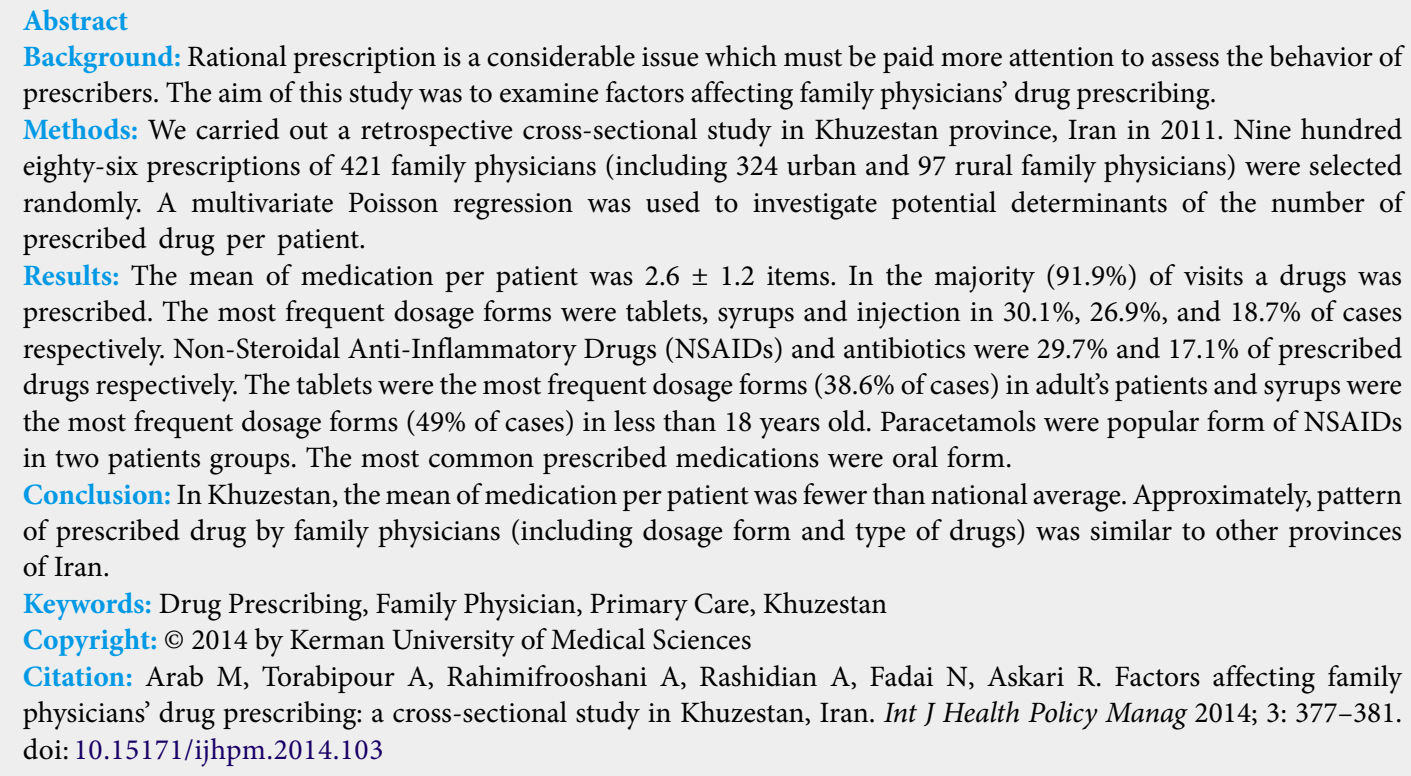

Background: Rational prescription is a considerable issue which must be paid more attention to assess the behavior of prescribers. The aim of this study was to examine factors affecting family physicians' drug prescribing.

Methods: We carried out a retrospective cross-sectional study in Khuzestan province, Iran in 2011. Nine hundred eighty-six prescriptions of 421 family physicians (including 324 urban and 97 rural family physicians) were selected randomly. A multivariate Poisson regression was used to investigate potential determinants of the number of prescribed drug per patient.

Results: The mean of medication per patient was $2.6 \pm 1.2$ items. In the majority (91.9\%) of visits a drugs was prescribed. The most frequent dosage forms were tablets, syrups and injection in $30.1 \%, 26.9 \%$, and $18.7 \%$ of cases respectively. Non-Steroidal Anti-Inflammatory Drugs (NSAIDs) and antibiotics were $29.7 \%$ and $17.1 \%$ of prescribed drugs respectively. The tablets were the most frequent dosage forms (38.6\% of cases) in adult's patients and syrups were the most frequent dosage forms (49\% of cases) in less than 18 years old. Paracetamols were popular form of NSAIDs in two patients groups. The most common prescribed medications were oral form.

Conclusion: In Khuzestan, the mean of medication per patient was fewer than national average. Approximately, pattern of prescribed drug by family physicians (including dosage form and type of drugs) was similar to other provinces of Iran.

Keywords: Drug Prescribing, Family Physician, Primary Care, Khuzestan

Copyright: (c) 2014 by Kerman University of Medical Sciences

Citation: Arab M, Torabipour A, Rahimifrooshani A, Rashidian A, Fadai N, Askari R. Factors affecting family physicians' drug prescribing: a cross-sectional study in Khuzestan, Iran. Int J Health Policy Manag 2014; 3: 377-381. doi: 10.15171/ijhpm.2014.103

Article History:

Received: 7 May 2014 Accepted: 19 October 2014 ePublished: 20 October 2014

\footnotetext{
${ }^{*}$ Correspondence to: Amin Torabipour Email: torbi-a@ajums.ac.ir
}

\section{Key Messages}

Implications for policy makers

- The result of this paper can help health managers and policy-makers to find the cause of the inappropriate prescriptions by family physicians.

- Also the results can help policy-makers to analyze and assess the prescribing behavior of Iranian family physicians.

Implications for public

Generic drug prescription policies and prescribing behavior of physicians impact on the health economic status and community's health; hence, factors affecting prescribing behavior of family physicians and General Practitioners (GPs) should be assessed in order to improve the demand and supply chain of generic drugs and community's health.

\section{Introduction}

In the recent years, the Ministry of Health and Medical Education (MoHME) in the Islamic Republic of Iran has focused on the primary healthcare and referral system (1). In 2005, a Family Physician Program (FPP) was implemented in all rural areas and cities with less than 20,000 populations (2-4). According to this program, every family physician should prescribe drugs rationally just for first-level patients. Also they were prescribing less than 270 types of essential generic drug. These restrictions of drug prescription lead to reduce the number of drugs per prescription and change of prescription pattern by General Practitioners (GPs) (4). Since 2012, FPP was implemented as a pilot in some cities with 20,000-50,000 population in three provinces of Iran including: Khuzestan, Sistan-va-Bluchestan and Cheharmahal Bakhtiari (5). Family medicine has been in conflict about whether it is a special or general discipline (6). In Iran, GPs play role of family physicians. Family physicians are skilled physicians that have been empowered in the care of patients with acute and chronic problems. They are skilled in assessing effectiveness of the care in a practice (7). Family physician as a gatekeeper can make decisions about the appropriate use of health resources. Gatekeepers help patients to identify their health needs and select services efficiently (8). They reduce health expenditures and improve the health outcomes (9). Rational prescription of medicines is an important issue 
Table 2. Descriptive statistics of the less than 18 years old $(n=275)$

\begin{tabular}{|c|c|c|}
\hline Variables & & Number (\%) \\
\hline \multicolumn{3}{|l|}{ Gender } \\
\hline & Male & $133(48.4)$ \\
\hline & Female & $142(51.6)$ \\
\hline \multicolumn{3}{|l|}{ Age/year } \\
\hline & $<1$ & $48(17.5)$ \\
\hline & $1-10$ & $156(56.7)$ \\
\hline & $11-18$ & $71(25.8)$ \\
\hline \multicolumn{3}{|c|}{$\begin{array}{l}\text { Type of health } \\
\text { insurance* }\end{array}$} \\
\hline & Rural health insurance plan & $226(82.2)$ \\
\hline & Medical services organization & $32(11.6)$ \\
\hline & Social security fund & $11(4.0)$ \\
\hline & Militarily force insurance & $6(2.2)$ \\
\hline \multicolumn{3}{|c|}{$\begin{array}{l}\text { The Number of } \\
\text { visits/year }\end{array}$} \\
\hline & 1 & $125(45.5)$ \\
\hline & 2 & $121(44.0)$ \\
\hline & 3 & $24(8.7)$ \\
\hline & $4 \leq$ & $5(1.8)$ \\
\hline \multicolumn{3}{|c|}{$\begin{array}{l}\text { The main } \\
\text { complaints }\end{array}$} \\
\hline & Common cold & $172(62.5)$ \\
\hline & Fever & $85(30.9)$ \\
\hline & Sore throat & $12(4.4)$ \\
\hline & Stomach ache & $4(1.5)$ \\
\hline & Dysmenorrhea & $2(0.7)$ \\
\hline
\end{tabular}

fever (30.9\%) and sore throat (4.4\%) respectively (see Table 2). According to this study, in adults and children, the average of prescriptions per patient was $2.6 \pm 1.2$ and $1.2 \pm 0.5$ item respectively. A medications were not prescript in 80 (8.1\%) of prescription. In less than 18 years old group, in $29.1 \%$ of cases was prescript more than 3 items. In adults patients group, in $20 \%$ of cases was prescript more than 3 items. The most common dosage forms were: tablets (30.8\%), syrups (24.4\%), injection drugs (19.1\%), and capsules (9.8\%) respectively. In children, the most common used dosage forms were: tablets (13.7\%), syrups (49\%), injection drugs (12.5\%), and drops $(8.3 \%)$. Totally, the most frequent prescribed drugs were: Non-Steroidal Anti-Inflammatory Drugs (NSAIDs) (29.7\%), antibiotics (17.1\%), cough/cold drugs (11\%), and anti-allergy (9.7\%) respectively. In the less than 18 years old group, the most frequent prescribed drugs were: NSAIDs (28.6\%), antibiotics $(22.8 \%)$, cough/cold drugs (16.6\%), and anti-allergy (13.3\%) respectively. Paracetamol was prescript in $18.2 \%$ and $6.1 \%$ of cases for children and adults patient's respectively. Table 3 shows that the children and adults groups had a similar pattern in term of prescription of NSAIDs. The results show that oral medications were prescript more than others (see Table 3 ).

The results showed that patient's characteristics including: the main complaints and the number of visits per year had statistical significant effect on the number of drugs per prescription $(P<0.05)$. According to Poisson regression

Table 3. Compression of prescribed drugs between adults and children

\begin{tabular}{|c|c|c|c|c|}
\hline Variables & & Children* $(n=275)$ & Adults ( $n=711)$ & All patients ( $n=986$ ) \\
\hline \multirow{4}{*}{$\begin{array}{l}\text { Number of drug per patient } \\
\text { Mean } \pm S D=1.2 \pm 0.5\end{array}$} & 0 & $17(6.2 \%)$ & $63(8.9 \%)$ & $80(8.1 \%)$ \\
\hline & 1 & 19 (6.9\%) & $62(8.7 \%)$ & $81(8.2 \%)$ \\
\hline & $2-3$ & $159(57.8 \%)$ & $444(62.4 \%)$ & $603(61.2 \%)$ \\
\hline & $>3$ & $80(29.1 \%)$ & $142(20.0 \%)$ & 222 (22.5\%) \\
\hline \multirow{8}{*}{ Dosage form } & Tablet & $113(13.7 \%)$ & $712(38.6 \%)$ & 825 (30.8\%) \\
\hline & Syrup & 402 (49.0\%) & $251(13.6 \%)$ & $653(24.4 \%)$ \\
\hline & Ampule & 103 (12.5\%) & $408(22.1 \%)$ & 511 (19.1\%) \\
\hline & Capsule & $43(5.3 \%)$ & $220(11.9 \%)$ & $263(9.8 \%)$ \\
\hline & Ointment & $17(2.0 \%)$ & $103(5.5 \%)$ & $120(4.4 \%)$ \\
\hline & Drop & $69(8.3 \%)$ & $34(1.8 \%)$ & $103(3.8 \%)$ \\
\hline & Lotion & $10(1.2 \%)$ & 77 (4.1\%) & 87 (3.2\%) \\
\hline & Others & 75 (9.0\%) & $38(2.0 \%)$ & $113(4.2 \%)$ \\
\hline \multirow{11}{*}{ Type of drug } & NSAID & 235 (28.6\%) & $617(33.5 \%)$ & $852(29.7 \%)$ \\
\hline & Paracetamol** & $150(18.2 \%)$ & $112(6.1 \%)$ & 262 (8.9\%) \\
\hline & Antibiotics & $188(22.8 \%)$ & 312 (16.9\%) & 500 (17.1\%) \\
\hline & Cough/cold drugs & $137(16.6 \%)$ & $184(10.0 \%)$ & 321 (11.0\%) \\
\hline & Anti-allergy & $110(13.3 \%)$ & 175 (9.5\%) & 285 (9.7\%) \\
\hline & Anti-acid & $28(3.4 \%)$ & 157 (8.5\%) & 185 (6.3\%) \\
\hline & Antispasmodic & $10(1.2 \%)$ & $58(3.1 \%)$ & $68(2.3 \%)$ \\
\hline & Anti-hypertension & $2(0.3 \%)$ & 54 (2.9\%) & $56(1.9 \%)$ \\
\hline & Antifungal & $4(0.4 \%)$ & $49(2.6 \%)$ & $53(1.8 \%)$ \\
\hline & Anti-dyslipidemia & 1 (0.1\%) & $24(1.3 \%)$ & $25(0.8 \%)$ \\
\hline & Others & 107 (13.0\%) & 209 (11.3\%) & $316(10.8 \%)$ \\
\hline \multirow{4}{*}{ Form of use } & Oral*** & $627(77.3 \%)$ & $1217(65.9 \%)$ & $1844(68.8 \%)$ \\
\hline & Injection & $103(12.5 \%)$ & 408 (22.1\%) & 511 (19.1\%) \\
\hline & Topical & $27(3.2 \%)$ & $180(9.6 \%)$ & 207 (7.6\%) \\
\hline & Others & 75 (9.0\%) & $38(2.0 \%)$ & $113(4.2 \%)$ \\
\hline
\end{tabular}

${ }^{*}<18$ years; ** Paracetamols were included $63.8 \%$ of NSAIDs in children's group and $18.1 \%$ of NSAID in adults; ${ }^{* *}$ Oral medication including tablet, capsule, syrup, and drop. 
analysis, the some characteristics of physicians including: age, being native; and years of practicing had impact on the number of the prescribed drugs.

\section{Discussion}

Prescription is the most important function of a physician worldwide (19). Drug prescribing is one of the most common medical decisions by GPs (20). Drugs play an important role in general practicing. Studies show that in some countries, a medication is prescribed in $60 \%$ of visits (21). In this study, medication was prescribed in $91.9 \%$ of visits. In $8.2 \%$ of prescriptions one item, in $61.2 \%$ two items, and in $22.5 \%$ more than three items was prescribed. Enwere et al. found that the physicians prescribed the medication in $91 \%$ of visits (22), which their result was close to result of our study. According to audit report in Scotland, there was a minimum one prescription in $60 \%$ of physician's visits and more than $90 \%$ of the physicians had prescribed at least one medication. The studies showed that the number of prescribed drugs has been increased up to $33 \%$ in recent years. In 2012, twentyfour percent of Scotland population received 4 items of drug per prescription. Perhaps a reason of this increasing can be more contact of patients with general practices in the first line of the health network (23). Also Buusman et al. showed that GPs were responsible to $90 \%$ of the prescribed drugs (24). The results of our study showed that average number of drugs per prescription was 2.6. The result of our study was comparable with other studies in Iran (Table 4).

According to our results, the number of drugs per prescription in Khuzestan province was less than other provinces. In our study the poly-pharmacy term was defined for two and more drugs per prescription $(34,35)$. Other studies have considered more than five medications as a poly-pharmacy (36). Thus, in our study a considerable proportion of patients (83.7\%) experienced the poly-pharmacy. Some studies showed that there was relationship between poly-pharmacy and drug-related problems (34), unplanned hospitalization and adverse outcomes (37), increase of patients risk and costs (38), and adverse drug reactions and medication errors (39). According to results of our study, the most prescribed drugs were NSAID (29.7\%) and antibiotics (17.1\%) respectively. Wang et al. showed that $29.9 \%$ of the prescriptions were

Table 4. Comparison of the number of drugs per prescription in Iran and other countries (1998-2012)

\begin{tabular}{llll}
\hline Authors & Area & Year & Results \\
\hline Cheragali et al. (1) & National & 2004 & $3.4^{*}$ \\
& Khuzestan & 2004 & 3.7 \\
Shayan et al. (25) & Tabriz & 2006 & 4.5 \\
Shamsi et al. (26) & Lorestan & 2006 & 4.2 \\
Dinarvand and Nikzad (27) & Bam & 2008 & 3.5 \\
Alikhani et al. (28) & Tehran & 1998 & 3.6 \\
Zareshahi et al. (29) & Yasuj & 2006 & 3.6 \\
Mosleh et al. (30) & Kerman & 2012 & 3.1 \\
Ahmad Raza et al. (31) & Tehran & 2007 & 2.5 \\
Rahman et al. (32) & Pakistan & 2014 & 3.3 \\
Wang et al. (33) & Bangladesh & 2011 & 3.8 \\
\hline
\end{tabular}

*The number of drugs per prescription. included antibiotics (33). Kumari et al. reported that an antibiotic has been prescribed in $64.9 \%$ of the prescriptions. This prescription pattern was different in several geographic areas (40). A study showed that antibiotics were prescribed for $39.6 \%$ of the patients (41). Therefore, the result of this study was similar to some studies. Different factors impact on the decision to prescribe by physician. These factors include patient characteristics such as age, income status, type of disease and past experiences; and physician characteristics including gender, age, volume of practice and clinical skills; and other factors such as the number of primary care centers and social perceptions of illness $(19,42)$. Also prescription pattern is different between and within countries (43). The studies show that age of physicians and the number of physicians in a health center have a positive impact on the number of prescribed drugs (20). In our study, some physician characteristics including age, being native, and years of practicing had impact on the number of the prescribed drugs.

\section{Conclusion}

We concluded that the mean of the prescribed drugs per patient was less than national level. Approximately, pattern of drug prescribing (including dosage form and type of drugs) was similar to other provinces and NSAIDs were the most frequent prescribed drugs. In this study it was determined that being native, age of physicians and practicing years had significant relationship with the number of prescribed drugs. We recommend a more comprehensive study about factors influencing prescribing behavior of family physicians in national level.

\section{Acknowledgments}

The authors would like to thank the Research Deputy of Tehran University of Medical Sciences (TUMS) for their financial and administrative support to undertake this project.

\author{
Ethical issues \\ The ethical committee of Tehran University of Medical Sciences (TUMS) \\ approved the present study.
}

\section{Competing interests}

The authors declare that they have no competing interests.

Authors' contributions

MA and AT developed theoretical premise and conceptual model; RF and AR designed the research; NF and RA collected data; AT and RF analyzed data; MA drafted the manuscript; AT answered to the reviewers.

\section{Authors' affiliations}

'Department of Health Management and Economics, School of Public Health, Tehran University of Medical Sciences, Tehran, Iran. ${ }^{2}$ Department of Health Services Management, School of Health, Ahvaz Jundishapur University of Medical Sciences, Ahvaz, Iran. ${ }^{3}$ Department of Epidemiology and Biostatistics, School of Public Health, Tehran University of Medical Sciences, Tehran, Iran.

\section{References}

1. Cheraghali AM, Nikfar S, Behmanesh Y, Rahimi V, Habibipour $\mathrm{F}$, Tirdad R, et al. Valuation of availability, accessibility and prescribing pattern of medicines in the Islamic Republic of Iran. East Mediterr Health J 2004; 10: 406-15.

2. Takian A, Doshmangir L, Rashidian A. Implementing family 
physician programme in rural Iran: exploring the role of an existing primary health care network. Fam Pract 2013; 30: 5519. doi: 10.1093/fampra/cmt025

3. Khayati F, Motlagh MA, Kabir MJ, Kazemeini H, Gharibi F, Jafari $\mathrm{N}$. The role of family physician in case finding, referral, and insurance coverage in the rural areas. Iran J Public Health 2011; 40: 136-9.

4. Agenda of rural health insurance and Family physician plan in rural. Ministry of health, Islamic Republic of Iran, version 7.3; 2005.

5. Agenda of Family physician programme and referral system in urban. Ministry of health, Islamic Republic of Iran, version 02; 2012

6. Stein FS. Family Medicine's Identity: Being Generalists in a Specialist Culture? Ann Fam Med 2006; 4: 455-9.

7. Rosser W. Sustaining the 4 principles of family medicine in Canada. Can Fam Physician 2006; 52: 1191-2.

8. Forrest $\mathrm{CB}$. Primary care gatekeeping and referrals: effective filter or failed experiment? BMJ 2003; 326: 690-5. doi: 10.1136/ bmj.326.7391.692

9. Jaruseviciena J, Levasseu G. The appropriateness of gatekeeping in the provision of reproductive health care for adolescents in Lithuania: the general practice perspective. BMC Fam Pract 2006; 7: 16 . doi: 10.1186/1471-2296-7-16

10. Soleymani $F$, Valadkhani M, Dinarvand R. Challenges and achievements of promoting rational use of drugs in Iran. Iran $\mathrm{J}$ Public Health 2009; 38: 166-8.

11. World Health Organization (WHO). The selection and use of essential drugs: report of a WHO expert committee. WHO Technical Report Series No. 914. Geneva: WHO; 2003.

12. World Health organization (WHO). The rational use of drugs, Report of the Conference of Experts Nairobi, 25- 29 November 1985. Geneva: WHO; 1987.

13. Prosser H, Walley T. A qualitative study of GPs'and PCO stakeholders'views on the importance and influence of cost on prescribing. Soc Sci Med 2005; 60: 1335-46.

14. Crigger N, Holcomb L. Improving Nurse Practitioner Practice through Rational Prescribing. J Nurse Pract 2008; 4: 120-5. doi: 10.1016/j.nurpra.2007.12.004

15. Farrell VM, Hill VL, Hawkins JB, Newman LM, Learned RE Jr. Clinic for identifying and addressing polypharmacy. Am J Health Syst Pharm 2003; 60: 1830.

16. Choonara L. Rational prescribing is important in all settings. Arch Dis Child 2013; 98: 720. doi: 10.1136/archdischild-2013-304559

17. Afifi AA, Kotlerman JB, Ettner SL, Cowan M. Methods for Improving Regression Analysis for Skewed Continuous or Counted Responses. Annu Rew Public Health 2007; 28: 95-111. doi: 10.1146/annurev.publhealth.28.082206.094100

18. Famoye F, Wulu JT, Singh KP. On the Generalized Poisson Regression Model with an Application to Accident Data. J Data Sci 2004; 2: 287-95.

19. Neyaz Y, Qureshi NA, Khoja T, Magzoub MA, Haycox A, Walley $\mathrm{T}$, et al. Physicians' medication prescribing in primary care in Riyadh city, Saudi Arabia. Literature review, part 1: variations in drug prescribing. East Mediterr Health J 2011; 17: 126-31.

20. de Bakker DH, Coffie DS, Heerdink ER, van Dijk L, Groenewegen PP. Determinants of the range of drugs prescribed in general practice: a cross-sectional analysis. BMC Health Serv Res 2007; 7: 132. doi: 10.1186/1472-6963-7-132

21. Muijrers PE, Grol RP, Sijbrandij J, Janknegt R, Knottnerus JA. Differences in prescribing between GPs. Impact of the cooperation with pharmacists and impact of visits from pharmaceutical industry representatives. Fam Pract 2005; 22: 624-30. doi: 10.1093/fampra/cmi074

22. Enwere OO, Falade CO, Salako BL. Drug prescribing pattern at the medical outpatient clinic of a tertiary hospital in southwestern Nigeria. Pharmacoepidemiol Drug Saf 2007; 16: 1244-9.

23. Auditor General for Scotland. Prescribing in general practice in Scotland. 2013. Available from: http://www.audit-scotland.gov. uk/docs/health/2013/nr_130124_gp_prescribing.pdf

24. Buusman A, Andersen M, Merrild C, Elverdam B. Factors influencing GPs' choice between drugs in a therapeutic drug group. A qualitative study. Scand J Prim Health Care 2007; 25: 208-13.

25. Shayan Z, Shayan F. [Pattern of drug prescription in clinical wards of Motahari and Peymanieh hospital in Jahrom]. Medical Journal of Jahrom University of Medical Sciences 2006; 5 : 44-50. [In Persian]

26. Shamsi MM, Sepehri G, Farrokhi Noori MR, Mohsenbeighi M, Motevallizadeh HR. [Pattern of drug use among residents of Bam during the first 6 months after the 2003 earthquake]. Hakim Medical Journal 2008; 10: 27-33. [In Persian]

27. Dinarvand R, Nikzad A. [Condition of prescription and drug use in Tehran in 1998]. Hakim Medical Journal 2000; 3: 223-30. [In Persian]

28. Alikhani A, Shahamat M, Ghafarian SH. [Survey on antibiotic prescription for under 14 year old outpatients children in general practitioner prescription in Yasuj]. Journal of Yasuj University of Medical Sciences 2006; 10: 91-83. [In Persian]

29. Zareshahi R, Haghdoost AA, Asadipour A, Sadeghirad B. [Rational Usage of Drug Indices in the Prescriptions of Kerman Medical Practitioners in 2008]. Journal of Rafsanjan University of Medical Sciences 2012; 11: 523-36. [In Persian]

30. Mosleh A, Darbooy SH, Khoshnevis A, Mohammadi M. [Drug prescription based on WHO indicators: Tehran University of medical Sciences facilities with pharmacy]. Tehran University Medical Journal 2007; 65: 12-5. [In Persian]

31. Ahmad Raza U, Khursheed T, Irfan M, Abbas M, Irfan UM. Prescription patterns of general practitioners in Peshawar, Pakistan. Pak J Med Sci 2014; 30: 1-15.

32. Rahman M, Huq M, Rahman A. Study on the pattern of prescriptions available at rural households in Bangladesh. South East Asia Journal of Public Health 2011; 1: 12-6.

33. Wang H, Li N, Zhu H, Xu S, Lu H, Feng Z. Prescription Pattern and Its Influencing Factors in Chinese County Hospitals: A Retrospective Cross- Sectional Study. PLoS One 2013; 8: e63225. doi: 10.1371/journal.pone.0063225

34. Viktil KK, Blix HS, Moger TA, Reikvam A. Polypharmacy as commonly defined is an indicator of limited value in the assessment of drug-related problems. $\mathrm{Br} \mathrm{J}$ Clin Pharmacol 2006; 63: 187-95. doi: 10.1111/j.1365-2125.2006.02744.x

35. Brager R, Sloand E. The Spectrum of Polypharmacy. Nurse Pract 2005; 30: 44-50.

36. Sino CG, Sietzema M, Egberts TC, Schuurmans MJ. Medication management capacity in relation to cognition and selfmanagement skills in older people on polypharmacy. J Nutr Health Aging 2014; 18: 44-9. doi: 10.1007/s12603-013-0359-2

37. Payne RA, Abel GA, Avery AJ, Mercer SW, Roland MO. Is polypharmacy always hazardous? A retrospective cohort analysis using linked electronic health records from primary and secondary care. Br J Clin Pharmacol 2014; 77: 1073-82. doi: 10.1111/bcp.12292

38. Zarowitz BJ, Stebelsky LA, Muma BK, Romain TM, Peterson EL. Reduction of high-risk polypharmacy drug combinations in patients in a managed care setting. Pharmacotherapy 2005; 25: 1636-45.

39. Bjerrum L, Rosholm JU, Hallas J, Kragstrup J. Methods for estimating the occurrence of polypharmacy by means of a prescription database. Eur J Clin Pharmacol 1997; 53: 7-11.

40. Kumari KI, Chandy SJ, Jeyaseelan L, Kumar R, Suresh S. Antimicrobial prescription patterns for common acute infections in some rural \& urban health facilities of India. Indian J Med Res 2008; 128: 165-71.

41. Karande S, Sankhe P, Kulkarni M. Patterns of prescription and drug dispensing. Indian J Pediatr 2005; 72: 117-21.

42. Choi KH, Park SM, Lee JH, Kwon S. Factors Affecting the Prescribing Patterns of Antibiotics and Injections. J Korean Med Sci 2012; 27: 120-7. doi: 10.3346/jkms.2012.27.2.120

43. Magzoub MA, Neyaz Y, Khoja T, Qureshi NA, Haycox A, Walley T. Determinants of physicians' medication prescribing behavior in primary care in Riyadh city, Saudi Arabia. East Mediterr Health J 2011; 17: 160-6. 